\title{
Prevalence of Disabilities among Elderly in rural area at Assiut district, Egypt
}

\author{
Manal A. Mohammed ${ }^{1}$, Safaa A. Mohammed ${ }^{2}$, Nermeen M. Abd-Elaziz ${ }^{3}$. \\ ${ }^{1 .}$ Nursing Specialist in Health Administration Assiut Center, Egypt. \\ 2. Professor of Community Health Nursing, Faculty of Nursing, Assiut University, Egypt. \\ 3. Assistant Professor of Gerontological Nursing, Faculty of Nursing, Assiut University, Egypt.
}

\begin{abstract}
Background: In Egypt; Elderly populations are at higher risk than adult population for health problems and disability increase with increasing age. The study aimed to identify prevalence rate of disability among elderly at Assiut district. Subject and methods: cross sectional research design was utilized. Setting: The study was conducted in three randomly selected villages namely (Al-Shaghaba, Elwan and Awlad Ibrahim) at Assiut district. The total sample size was 1000 elderly after conducting home visit from the previous setting who were selected by convenient sample. Two tools were used, The $\mathbf{1}^{\text {st }}$ tool: A structured interview questionnaire sheet which included socio-demographic and medical data, The $2^{\text {nd }}$ tool: A questionnaire that assessed the levels of various disabilities among elderly people by Clifton Assessment Procedure for the Elderly and scale to asses activity of daily living. Results: (34.7\%) of studied elderly had mild impairment. While the mean \pm SD score of activity of daily living was $4.87 \pm 1.89$ Conclusion There was a positive correlation between elderly age and Clifton assessment procedures while a negative correlation was found between elderly age and Activity of Daily Living and the main percent of the studied elderly had mild impairment. Recommendation: Provide individualized education for elderly and their families to improve their knowledge about disability problems of elderly people.
\end{abstract}

\section{Keywords: Disabilities, Elderly \& Rural Areas.}

\section{Introduction}

Worldwide population of people 65 years and older is expected to reach 1.4 billion by 2030 , which will be $13 \%$ of the total population. In developed countries, the number of people aged 60 years and older is expected to rise from $22 \%$ to $30 \%$ during the 1 st 25 years of this century (Wang et al., 2016).

Egypt is the most crowded nation in the Middle East and the second nation on the continent of Africa. The people of Egypt account 1.2\% from the total people of world. In Egypt, the number of elderly people will increase to be $9.2 \%$ in 2021. By 2050, it is expected to become $20.8 \%$ of the over-all population in Egypt (World Health Organization, 2019).

In Upper Egypt, chronic diseases were one of important risk factor for disability. The prevalence rate of Activity Daily Living disability was $20.2 \%$. Activity Daily Living disability was sharply rising across age groups, Activity Daily Living disability among females $(20.5 \%)$ while in males $(19.8 \%)$ (Abou faddan et al., 2013).

Disability in activities of daily living is defined as difficulty with or an inability to perform self-care activities. Which include basic and instrumental activities. Because functional disability affects health status and the costs of long-term care, the prevention of functional disability among older people is increasingly important (Godber, 2018).

Rates of frailty and disability increase with increasing age among these elders. For example, inabilities to complete at least one activity of daily living increased from about $5-7 \%$ at ages $65-69$ years to about $28-$ $36 \%$ at ages $85+$ (Fleischmann, 2016).

Disability in basic activities of daily living (ADLs) implies a loss of independence and increases the risk for hospitalization, nursing home admission, and death. There is controversy, however, about how those declines relate to the health and functions of the survivors (Fleischmann, 2016).

Causes of disability among older adults are: chronic diseases, injuries, mental impairment, malnutrition, human immunodeficiency virus (HIV/AIDS) and other communicable diseases. The main chronic conditions of an aging society include: cardiovascular diseases, hypertension, stroke, diabetes, cancer, chronic obstructive pulmonary disease, muscularskeletal conditions including arthritis and osteoporosis, mental health conditions such as dementia and depression, blindness and visual impairment (Al Saedi et al., 2019). 
Recent declines in the prevalence of disability may be due to increased use of assistive technologies and changes in the respondents' perceptions of "disability" over time. Population ages, disability is becoming an increasingly important public health problem. Recent evidence has demonstrated that disability is a dynamic process with multiple recurrent episodes (Agree, \& Wolf, 2017).

Impairment in a person's body structure or function, or mental functioning; examples of impairments include loss of a limb, loss of vision or memory loss. Activity limitation, such as hardness seeing, hearing, walking, or problem solving. Participation restrictions in normal daily activities, such as working, engaging in social and recreational activities, and obtaining health care and preventive services (WHO, 2015).

The role of gerontological nurse in disability among elderly are educate persons of all ages improve activities that lead to healthy aging and prevent disability and also provide individualized education for elderly and their families, assess and provide interventions related to nursing diagnoses, realize and decrease risks (Charlotte, 2020).

Nurses promote self-care capacity and independence , advocate for and conserve the rights of older adults , promote the use of ethics and standards in the care of older adults and help older persons face the transition to death with peace, comfort, and dignity (Charlotte, 2020).

Gerontological nurses provide responsive care that facilitates and empowers client independence through life course changes. A responsive care approach recognizes that certain behaviors are not necessarily related solely to pathology, but instead may be related to circumstances within the physical or social environment surrounding well older persons (Anrys et al., 2019).

Nurses need to assess family caregivers for emotional distress and intervene to reduce distress by fostering patient-caregiver teamwork, communication, and self-care; providing information; and referring to resources as needed (Myers et al., 2019).

\section{Significance of the study}

The ageing population has become a global phenomenon, (Falahaty et al., 2015) According to Central Intelligence Agency, (2020) reported that, Egypt's elderly population had reached 6.5 million; 3.5 million males and 3 million females and will increase in 2050 to 18.1 million elderly. Also, the Egyptian life expectance 2019 is 71.90 years: 68.2for male and 73.0 years for female.

In Egypt; Elderly populations are at higher risk than adult population for health problems. The greatest risks for health problems are for people over the age of 75. The prevalence of most chronic disease increases with age, so does the prevalence of definite disability. The prevalence of functional impairment increases with age from $13 \%$ among persons aged 65 to 69 years to $35 \%$ among those aged 85 years and older (Rasheedy, 2015).

Many chronic illnesses can influence the quality of life in elderly populations, and there is evidence that there is increased risk of multiple comorbidities in elderly populations that may lead to disability. A number of morbidity patterns have been realized in elderly populations, which include "hypertension, diabetes, arthritis, and constipation, cataracts and hearing loss. (Agrawal, 2016). So, this study will be carried out to identify the prevalence of disability among elderly in rural area at Assiut district.

The statistic describes the disability prevalence rates across Egypt in 2016, by gender. As of 2016, the disability prevalence rate in Egypt for men was about 2.24 percent compared to 1.59 percent for women (Hwait et al., 2020).

Aim of the study

The aim of this study was to identify prevalence of disability among elderly in rural area at Assiut district.

\section{Research question}

1- What is the prevalence of disabilities among elderly in rural area at Assiut district?

2- Are the disabilities among elderly affecting physical and social activities?

\section{Subjects and Methods}

Research design: Cross sectional research design was used in this study.

Setting: The study was conducted in Al-Shaghaba, Elwan village and Awlad Ibrahim village at Assiut district.

Sample: Random sample were used to select three villages from Assiut district which consist from 30 villages by simple random sample the three villages (400 elderly from Al-Shaghaba village, 300 elderly from Elwan village and 300 elderly from Awlad Ibrahim village) were selected from total number. The previous mention three villages was completely covered by home visit to cover the total number of elderly in each village which was found as follow(400 elderly from Al-Shaghaba village, 300 elderly from Elwan village and 300 elderly from Awlad Ibrahim village) which was agree to share in the study. By convenient sample the total sample size was 1000 elderly (aged from 60 years and more).

The study conducted for 6 months starting from the $1^{\text {st }}$ of January to the end of June (2019), three days a week. The average number, which interviewed was 12 to 14 elderly per day from every village and the average time taken for completing each sheet was around 25-30 minutes. 
Study tools

Data collected using two tools

Tool I: A structured questionnaire sheet, consisted of 2 parts:-

The $1^{\text {st }}$ part was included socio-demographic characteristics, which include (name, age, gender, marital status, educational level, work condition and source of income) (Abd El- Twaab, 2012).

The $2^{\text {nd }}$ part included medical history of chronic illness as (hypertension, diabetes, cardiovascular disease, musculoskeletal disease, chest disease, gastrointestinal disease, hearing impairment and visual impairment).

Tool II: A questionnaire that assessed the levels of various disabilities in the elderly.

It includes two parts:

Part (1): The Clifton Assessment Procedure for the Elderly $\{$ CAPE $\}$ :

Contained 18 items covering four areas: physical disability, apathy or inactivity, communication difficulties and social disturbance (Pattie and Gilleard, 1979).

Persons who could do the task without help were considered not to have the qdisability. Persons who could not do the task or could do it only with help were considered to have the disability according to the following:

A (No impairment): independent elderlycomparable to those living without support in the community.

B (Mild impairment): low dependency - like to include those needing some support in the community, warden assisted accommodation and the better residents in residential accommodation;

C (Moderate impairment): medium dependencypeople functioning at this level are likely to need residential care or considerable support and help if at home;

D (Marked impairment): high dependency-it is within this category that there is greatest overlap between those in social services accommodation and those in hospital care;

E (Severe impairment): maximum dependency- this level is seen often in psychologeriatic wards and the ones who remain in community homes, often present considerable problems to staff in terms of their demands on staff time.

\begin{tabular}{|c|c|c|c|c|c|}
\hline Grads & A & B & C & D & E \\
\hline $\begin{array}{c}\text { Behaviour } \\
\text { Rating } \\
\text { Scale total }\end{array}$ & $0-3$ & $4-7$ & $8-12$ & $13-17$ & $18+$ \\
\hline
\end{tabular}

Part (2): Katz Index of Independence in Activities of Daily Living (Katz et al., 1970).

Commonly referred to as the Katz ADL, is the most appropriate instrument to assess functional status as a measurement of a client's ability to perform activities of daily living independently. Disability is defined as the need for personal assistance in bathing, dressing, walking inside the house, or transferring from a chair. Chronic disability is much more prevalent among the elderly, and it has a more direct impact on the demand for medical care.

This tool aimed to assess physical disability, an objective measurement of the person's ability to perform ADL were used independently, included performance a 6-item index that gives an assessment of the performance in the six functions of bathing, dressing, toileting, transferring, continence, and feeding. For this study, physical disability was defined as needing help in one or more of these ADL activities.

Scoring system for Activities of daily living consist from six item it ranged between (1or 0 ) .The score of independence represent (1points), while the score of dependence represent ( 0 points)

The high score of elderly independent represent 6 degree, while the low score of elderly very dependent represent score of zero .

Validity \& Reliability of the tools

Tools were tested for their content validity by a group of five experts in community health and gerontological nursing. The required modifications were done. Test of the study tools' reliability was done by to alpha Cronbach test $(\mathrm{r}=0.84)$, alpha $=$ 0.77. The data were collected from the subjects after assurance of confidentiality of the data and obtaining informed written consent from them.

\section{Methods}

\section{Administrative stage}

It includes the following activities: the responsible authorities at the previously mentioned research setting to collect the necessary data for this study.

An official approval letter was obtained from the dean of faculty of nursing at Assiut University to undersecretary of the ministry of health at Assiut directorate of health to obtain the permission for carrying out this study.

Elderly consent for participation in the study after explaining the aim of the study and confidentiality of obtained data will be taken.

Pilot study

A pilot study was carried out of $10 \%$ of the studied elderly, which excluded from the study subject. Then some significant modifications were done to avoid the ambiguous of the questionnaire.

\section{Ethical Consideration}

1. Research proposal was approved from Ethical Committee in Faculty of nursing.

2. There is no risk for study subjects during application of research. 
3. The study was follow common ethical principles in clinical research.

4. Written consent was obtained from elderly people that are willing to participate in the study, after explaining the nature and purpose the study.

5. Elderly people was assured that the data of this research will not be reused without second permission.

6. Confidentiality and anonymity was assured.

7. Elderly peoples have the right to refuse to participate and/ or withdrawal from the study without any rational any time.

\section{Data collection}

was conducted during the period of 6 months from the $1^{\text {st }}$ January to the end of June (2019) through three days a week. The average number of the interviewed was 12-14 elderly per day from every village and the average time taken for completing each sheet was around 25-30 minutes.

The researcher interviewed the elderly also obtained from close family members of those elderly who were unable to give the required details according to their circumstances in order to obtain the necessary information. The aim of the study was briefly explained through direct communication with each elderly.

\section{Statistical analysis}

Data entry and data analysis were done using SPSS version 22 (Statistical Package for Social Science). Data was presented as number, percentage, mean and standard deviation. Chi-square test was used to compare qualitative variables. Pearson correlation was done to measure the correlation between quantitative variables. P-value considered statistically significant when $\mathrm{P}<0.05$.

\section{Results}

Table (1): Distribution of the studied elderly according to their socio-demographic characteristics in rural area at Assiut district.

\begin{tabular}{|c|c|c|}
\hline Variables & No. (1000) & $\%$ \\
\hline \multicolumn{3}{|l|}{ Age: (years) } \\
\hline $60<65$ & 266 & 26.6 \\
\hline $65-70$ & 404 & 40.4 \\
\hline$>70$ & 330 & 33.0 \\
\hline Mean \pm SD (Range) & \multicolumn{2}{|c|}{$69.11 \pm 6.38(60.0-96.0)$} \\
\hline \multicolumn{3}{|l|}{ Sex: } \\
\hline Male & 531 & 53.1 \\
\hline Female & 469 & 46.9 \\
\hline \multicolumn{3}{|l|}{ Level of education: } \\
\hline Illiterate & 532 & 53.2 \\
\hline Primary & 336 & 33.6 \\
\hline Preparatory & 50 & 5.0 \\
\hline Secondary & 60 & 6.0 \\
\hline University & 22 & 2.2 \\
\hline \multicolumn{3}{|l|}{ Occupation before retirement: } \\
\hline Working & 330 & 33.0 \\
\hline Not working & 670 & 67.0 \\
\hline \multicolumn{3}{|l|}{ Social class: } \\
\hline Low & 215 & 21.5 \\
\hline Middle & 612 & 61.2 \\
\hline High & 173 & 17.3 \\
\hline \multicolumn{3}{|l|}{ Residential place: } \\
\hline El-Shaghaba & 400 & 40.0 \\
\hline Awlad Ibraheem & 300 & 30.0 \\
\hline Elwan & 300 & 30.0 \\
\hline
\end{tabular}




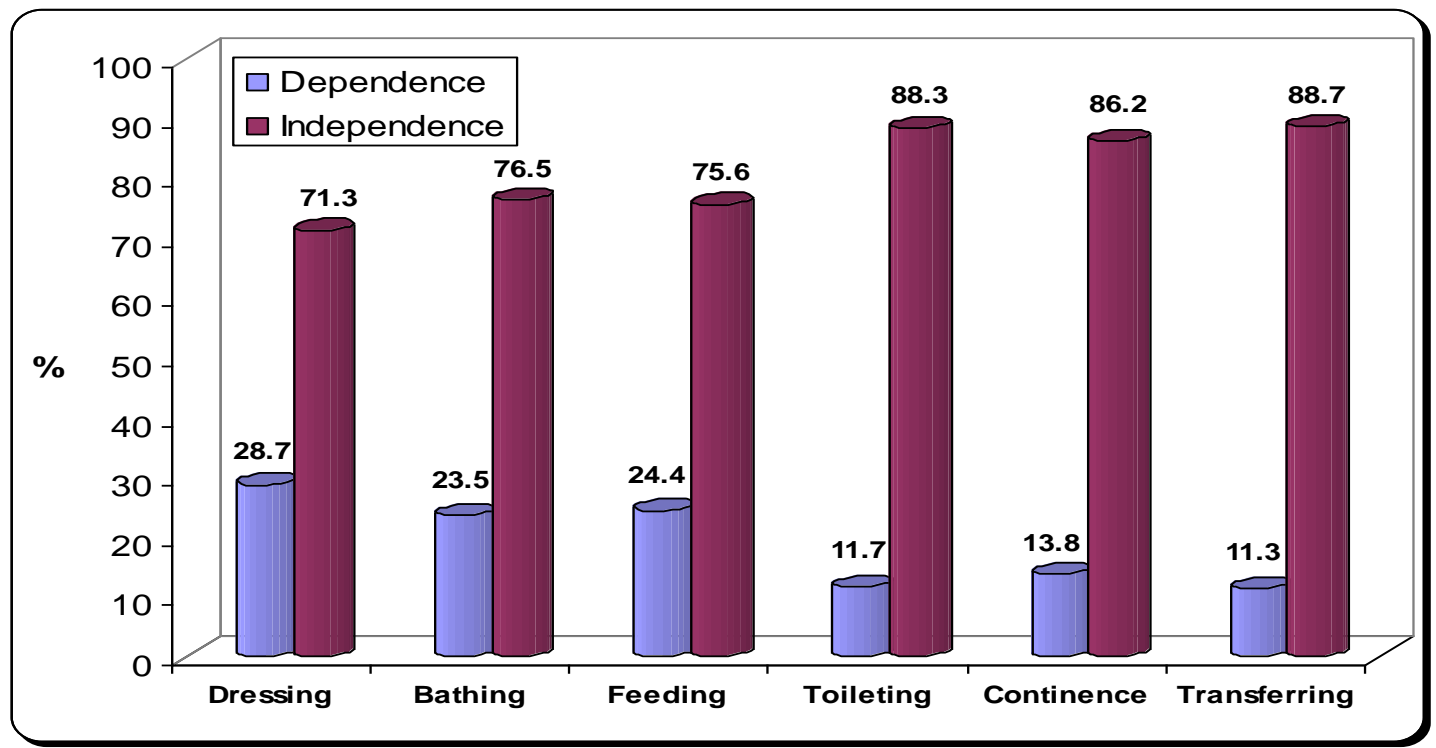

Figure (1): Distribution of the studied elderly according to their Activity of Daily Living in rural area at Assiut district.

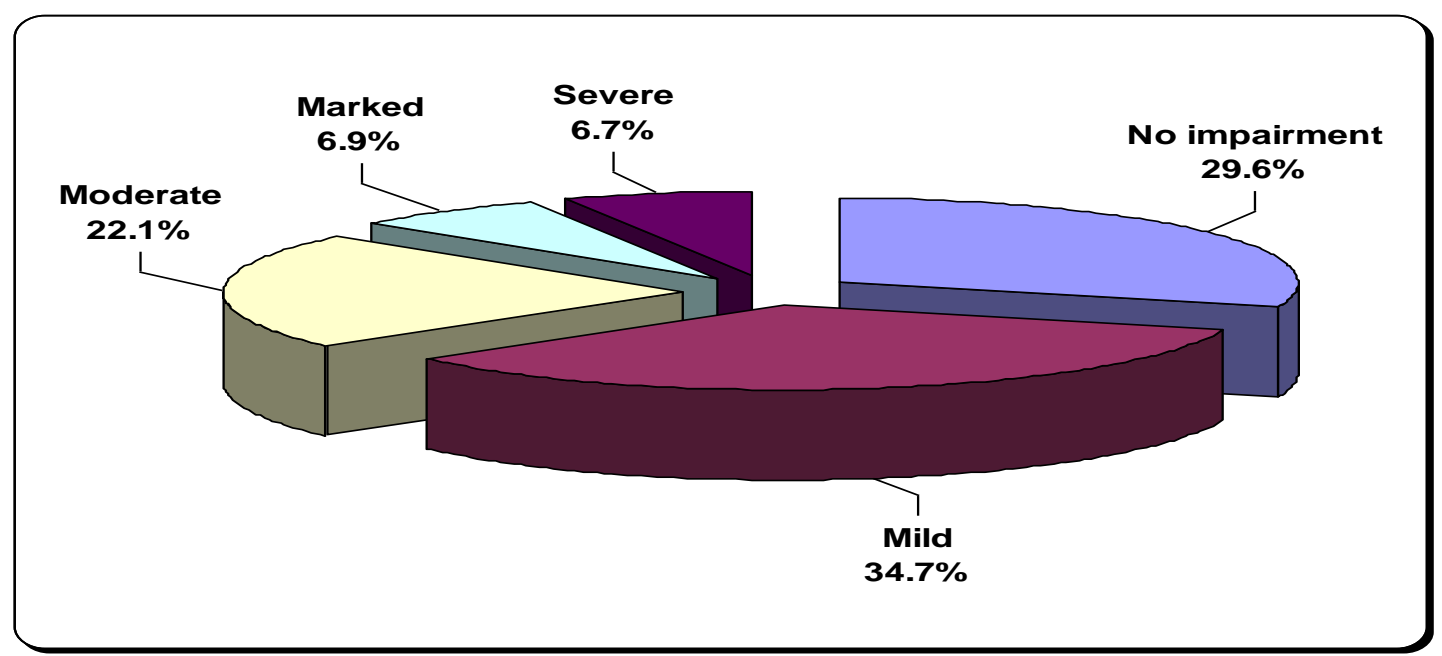

Figure (2): Distribution of the studied elderly according to dependency grade in rural area at Assiut district.

Table (2): Mean score of total Clifton assessment procedure and total activity of daily living for elderly in rural area at Assiut district.

\begin{tabular}{|l|c|c|}
\hline \multicolumn{1}{|c|}{ Variables } & Mean \pm SD & Median \\
\hline Total Clifton Assessment Procedures & $7.03 \pm 5.32$ & $6.0(0.0-28.0)$ \\
\hline Physical disability & $1.98 \pm 2.30$ & $1.0(0.0-12.0)$ \\
\hline Apathy and inactivity & $3.54 \pm 2.49$ & $3.0(0.0-10.0)$ \\
\hline Communication difficulties & $0.32 \pm 0.72$ & $0.0(0.0-4.0)$ \\
\hline Social disturbance & $1.20 \pm 0.97$ & $1.0(0.0-5.0)$ \\
\hline Activity of daily living & $4.87 \pm 1.89$ & $6.0(0.0-6.0)$ \\
\hline
\end{tabular}




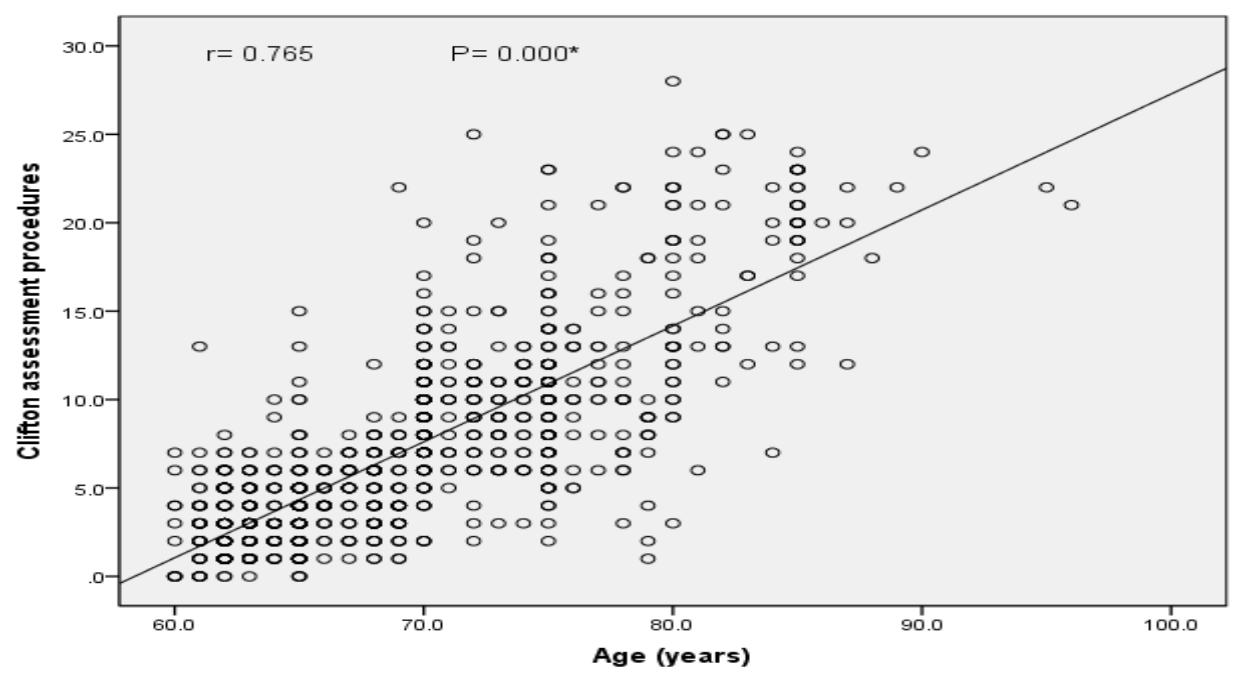

Fig. (3): Correlation between elderly age and Clifton assessment procedures score.

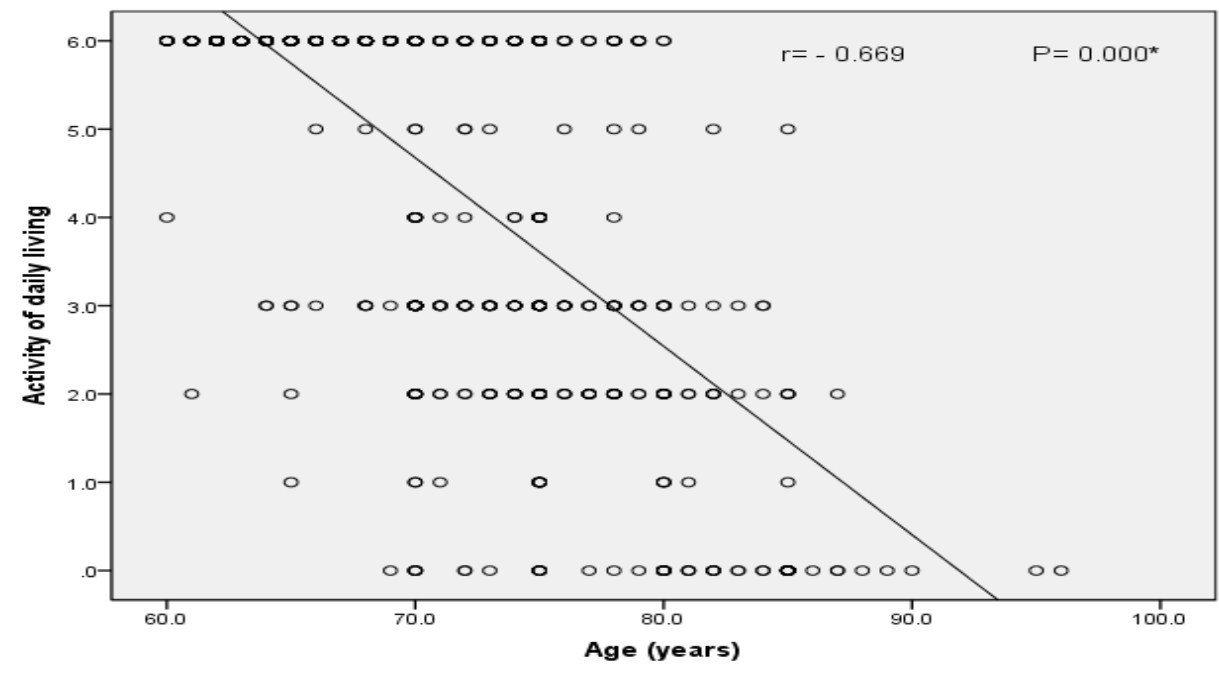

Fig . (4): Correlation between elderly age and activity of daily living score.

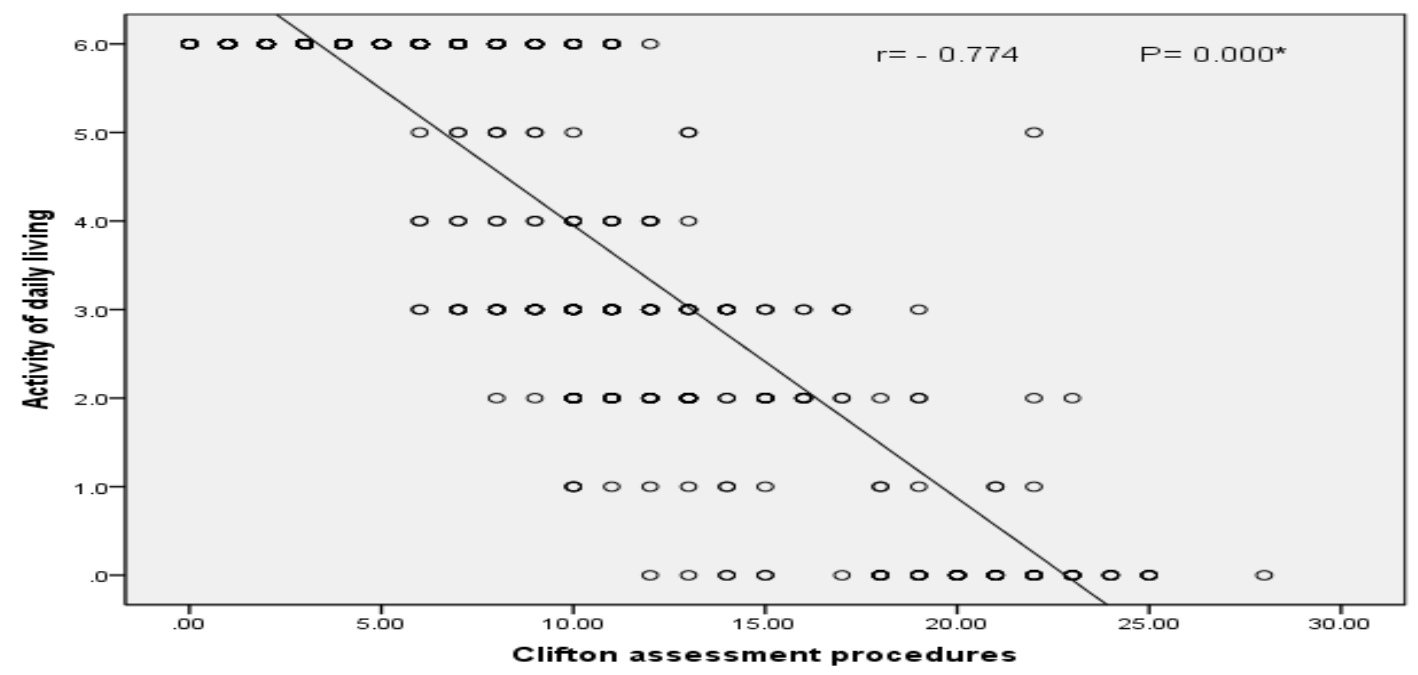

Figure (5): Correlation between Clifton assessment procedures and activity of daily living in rural area at Assiut district. 
Table (1): Showed that distribution of the studied elderly according to their socio-demographic characteristics in rural area at Assiut district, regarding to their ages, About two fifth $(40.4 \%)$ of the studied elderly ranged from 65 to 70 years old with mean \pm SD and range $69.11 \pm 6.38(60.0-96.0)$. More than half of the studied elderly was male and illiterate (53.1\% and 53.2\% respectively) and more than two third of participants $(67.0 \%)$ was not working. About two third (61.2\%) of the studied elderly social class was middle and two fifth $(40 \%)$ of them were from El-Shaghaba village.

Figure (1): Revealed that distribution of the studied elderly according to their activity of daily living in rural area at Assiut district, the most of them were independent regarding (dressing, bathing, feeding, toileting, continence and transferring (71.3, 76.5, $75.6,88.3,86.2$, and 88.7 respectively).

Figure (2): Showed the distribution of the studied elderly according to dependency grade in rural area at Assiut district, the more than one third of the studied elderly had mild impairment (34.7\%).

Table (2): Revealed that the mean score of total Clifton assessment procedure and total activity of daily living for elderly in rural area at Assiut district, the mean \pm SD of total Clifton Assessment procedures was $(7.03 \pm 5.32)$ regarding (Physical disability, apathy \& inactiity, communication difficulties and social disturbance $(1.98 \pm 2.30,3.54 \pm$ $2.49,0.32 \pm 0.72$, and $1.20 \pm 0.97$ respectively) while the total score of activity of daily living was $4.87 \pm$ 1.89 .

Figure (3): Revealed that a positive correlation between elderly age and Clifton assessment procedures scores in rural area at Assiut district $\mathrm{r}$. $=0.756$ and $P$. value $=0.001 *$.

Figure (4): Showed a negative correlation between elderly age and activity of daily living scores in rural area at Assiut district r. $=-0.669$ and P. value $=0.001^{*}$.

Figure (5): Showed there was a negative correlation between Clifton assessment procedures and activity daily living scores for elderly in rural area at Assiut district $\mathrm{r} .=-0.774$ and $\mathrm{P}$. value $=0.001 *$.

\section{Discussion}

The study clear that regarding to socio-demographic characteristics of elderly people in rural area at Assiut district ,about two fifth of them their age ranged from 65 to 70 years old with mean \pm SD 69.11 $\pm 6.38(60.0-96.0)$. This match with Khan, et al., (2018) who studied that " Correlates of physical disability in the elderly population" in rural North India, that; the prevalence of physical disability in elderly people aged 60 years and above. Also this agree with Tareque et al., (2017) who studied the rates of mild, moderate and severe/extreme disability in adults aged 75 and older were 39.17, 15.31 and $10.14 \%$, respectively.

In the other hand this dis agreed with Hosseinpoor et al., (2016) study entitled " Socio-demographic patterns of disability among older adult populations of low-income and middle-income countries: results from World Health Survey " who demonstrates that disability prevalence, the oldest of the elderly (above 80 years).

In the present study found more than half was male and illiterate and more than half was not working. It can be inferred that the majority of studied patients live in rural areas where the level of education are minimal. This result disagreed with Goswami et al., (2019) who found in the study " Disability and its association with sociodemographic factors among elderly persons residing in an urban resettlement colony " that two fifths of the studied samples had primary education.

Contrary to previous findings, Kessler, (2015) demonstrates that disability prevalence is higher among women, those not currently married. Female sex was associated with higher disability prevalence, a trend which has been widely reported across epidemiological studies (Vetvik et al., 2017). The years of life spent living with a disability has been estimated to be twice as long in women, who have longer life expectancies (Freedman et al., 2016). On the other hand, there have also been reports of similar disability rates between sexes or male-favorable situations, as a minority of our country specific results indicated (Sienko, 2017).

The present study showed that about two third of elderly participants had middle social class. This disagreed with Schmukle et al., (2019) who studied income inequality and and its effect on generosity, who found that more than three fifths of participants had sufficient income and low social class.

It seems that targeted interventions in the field of physical activity and lifestyle in the elderly might also be modified. The elderly at home and elderly living in villages away from the City, who do not have access to elderly health services provided at health centers (Zhang et al., 2019).

Regarding to physical disability the present study showed that the majority of the studied elderly not required any assistance when bathing or dressing, regarding to walking, more than one third of them showed no signs of weakness, most of them never had incontinent of urine and or feces.

Incongruities between physical functioning and disability status may reflect differences in individual perception of ability to complete a specific task or a different level of adaptation to functional limitations, which has been observed in other study by Mozafari 
et al., (2016) on functional limitation and selfreported disability status has documented discord in responses among individuals who could not complete a performance-based task, but reported no difficulties in self-assessments of functional capacity

Consistent with the current findings, the results of the study by Bleijenberg et al., (2017) showed in the study of " Disability in the individual ADL, IADL, and mobility among older adults " that the older people experienced a higher level of disability in the areas of bathing and less disability in eating.

This discrepancy can be due to the different setting of population in terms of culture, place of residence, and the tools used in each of the studies. On the other hand, lack of knowledge regarding the use of medical rehabilitation and auxiliary equipment for daily activities in Assiut city can have a major impact on the elderly's disability and might be among the other causes of discrepancies in different studies.

Besides, the application of training and programs for using diets enriched by calcium and Vitamin D in accordance with the cold mountainous region can also contribute to the reduction of skeletal diseases and, consequently, disability of the elderly (Hosseini et al., 2014). One of the findings of current research is a relationship between age and disability in the elderly suggesting that some disabilities in older people increase with age.

The present study revealed distribution of the studied elderly according to their activity of daily living in rural area at Assuit district, the most of them had an independent level regarding (dressing, bathing, feeding, toileting, continence and transferring. Disability rates for elderly people are also on the rise with an increase in the burden of chronic diseases depriving them of independence and the performance of activities of daily living.

However, Pradhan, (2016)in the study of "Social integration and its correlation with loneliness" who covering a sample of 4000 subjects representative of the non-institutionalized Spanish population aged 60 years revealed that over $19.1 \%$ had ADL disability.

This disagree with another study carried out in Singapore, the results was higher than their results which revealed that the prevalence of disability in at least one of five ADL items was $6.6 \%$ in those aged $\geq$ 65 (Mary-Heck et al., 2018).

The present study showed the distribution of the studied elderly according to dependency grade in rural area at Assuit district, the more than one third of them had mild impairment. This result supported previous studies Fong, (2019) who found in the research entiteled " Disability incidence and functional decline among older adults with major chronic diseases " that older adults with dementia who showed a greater inability to perform activities of daily living independently were more likely to exhibit behavioral dysfunctions.

Nomura et al., (2017) found that, disability makes a person dependent on others for support and care and also increases the burden on the health system.

The present study revealed the distribution of studied elderly according to their mean score of total Clifton assessment procedure and total activity of daily living at rural area in Assuit district, the mean \pm SD of total Clifton Assessment procedures was $(7.03 \pm 5.32)$ regarding (Physical disability, apathy and inactivity, communication difficulties, and social disturbance) while the total score of Activity of daily living was $4.87 \pm 1.89$.

This result was similar to a previous study of Alegría et al., (2019) stressed in their study " Effectiveness of a disability preventive intervention for minority and immigrant elders " that additional chronic illnesses can cause inactivity or decrease physical activity and result in greater dependence in daily functioning.

In addition, as people age there are increased chances of becoming disabled, and once disabled, there are increased chances of deterioration with decreased likelihood of recovering from disability (Banjare and Pradhan, 2014)

The present study showed that there was a negative correlation between elderly age and activity of daily living. This match with Gupta et al., (2016) in the study " Assessment of physical disability using Barthel index among elderly of rural areas " in India , that Physical disability increased significantly with the increasing age of participants; the same has been reported consistently in the previous studies.

Abd El-Mottelb et al., (2018) added, in the study "Predicators of successful aging among academic emeritus" more than half of the elderly aged 75 years and above were physically disabled as per 10 item ADL index. Norliana, (2016) in a study conducted in Malaysia and Nigeria also reported 10 item ADL disability in less than half of the elderly aged 75 years and above.

The present study showed there was a negative correlation between Clifton assessment procedures and activity daily living scores for elderly in rural area at Assuit district. Popolo et al., (2017) found that among older adults, were correlated with poorer daily functioning. Speculated that long-term chronic illnesses affected the participants' physical activity, affected their abilities to perform physical activity and/or daily functioning. Moreover, participants in this study had poorer upper body flexibility and upper limb muscle endurance than did older adults.

\section{Conclusion}

More than one third of the studied elderly had mild impairment however; there was a positive correlation 
between the studied elderly ages and Clifton assessment procedures but a negative correlation between elderly age and activity daily living with statistically significant differences. About two third of the studied elderly had middle social class. There was a negative correlation between Clifton assessment procedures and activity daily living scores.

\section{Recommendations}

- An educational program to raise the level of awareness regarding problem of disabilities among elderly people through improve activities that lead to healthy aging.

- Provide individualized education for elderly and their families to improve their knowledge about disability problems of elderly people.

- Further studies should be done to investigate and determine the factors influencing disabilities among elderly.

\section{References}

1. Abd El-Mottelb, B., Mo'Awad, E., \& ElDin, S., (2018): Predicators of successful aging among academic emeritus. Egyptian Nursing Journal, 15(2), 144.

2. Abd EL-Twaab (2012): Socio economic scale, faculty of education, Assiut University.

3. Abou Faddan H., Mohammed H., Darwish M., \& Zarzour A., (2013): Morbidity profile and its relationship with disability among elderly people residing geriatric homes and attending geriatric social clubs in assiut city, Egypt Vol. 11, N. 3.

4. Agrawal A., (2016): Disability among The elder population of India: A public health concern Vol: 30 / issue 1 p: 15-19.

5. Agree, E., \& Wolf, D., (2017): Disability Measurement in the Health and Retirement Study. In Forum for Health Economics and Policy (Vol. 21, No. 1). De Gruyter.).

6. Al Saedi, A., Feehan, J., Phu, S., \& Duque, G., (2019): Current and emerging biomarkers of frailty in the elderly. Clinical interventions in aging, 14, 389.

7. Alegría, M., Frontera, W., Cruz-Gonzalez, M., Markle, S., Trinh-Shevrin, C., Wang, Y., \& Guo, Y., (2019): Effectiveness of a disability preventive intervention for minority and immigrant elders: the positive mindsstrong bodies randomized clinical trial. The American Journal of Geriatric Psychiatry, 27(12), 1299-1313.

8. Anrys, C., Van Tiggelen, H., Verhaeghe, S., Van Hecke, A., \& Beeckman, D., (2019): Independent risk factors for pressure ulcer development in a high-risk nursing home population receiving pressure ulcer prevention. In CARE4 International Scientific Nursing and Midwifery Congress, Third Edition.

9. Banjare P., \& Pradhan J., (2014): Socioeconomic inequalities in the prevalence of multi-morbidity among the rural elderly in Bargarh District of Odisha (India). PloS one;9:e97832.

10. Bleijenberg, N., Zuithoff, N., Smith, A., De Wit, N., \& Schuurmans, M., (2017): Disability in the individual ADL, IADL, and mobility among older adults: a prospective cohort study. The journal of nutrition, health \& aging, 21(8), 897-903.

11. Central Intelligence Agency, (2020): Egypt Demographics Profile 2020, Available at: https://www.indexmundi.com/egypt/demograp hics_profile.html.

12. Charlotte E., (2020): Gerontological Nursing. Seventh edition Chapter (10), P: 123 by J.B.Lippin CO.

13. Falahaty K., Cheong L., \& Isa M., (2015): Disability among Elderly People with Visual Impairment in Two Welfare Homes in Malaysia. Biomed pharmacol J: 8(2).

14. Fleischmann, A., (2016): Suicide in the world. Suicide: An unnecessary death, $3^{\text {rd }}$ ed, chapter1, 3-17.

15. Fong, J., (2019): Disability incidence and functional decline among older adults with major chronic diseases. BMC geriatrics, 19(1), 323.

16. Freedman, V., Wolf, D., \& Spillman, B., (2016): Disability-free life expectancy over 30 years: a growing female disadvantage in the US population. American journal of public health, 106(6), 1079-1085.

17. Godber, K., (2018): Sport attainment and education sustainment of talented female secondary school athletes in New Zealand (Doctoral dissertation, Auckland University of Technology, 34- 38.

18. Goswami, A., Kalaivani, M., Nongkynrih, B., Kant, S., \& Gupta, S., (2019): Disability and its association with sociodemographic factors among elderly persons residing in an urban resettlement colony, New Delhi, India. PloS one, 14(9), e0222992-e0222992.

19. Gupta S., Yadav R., Malhotra A., (2016): Assessment of physical disability using Barthel index among elderly of rural areas of district Jhansi (U.P), India. J Family Med Prim Care. ;5:853-7.

20. Hwait, M., Ramadan, M., \& Abd Elfatah, A., (2020): Permanent Disability between 
Current Medicolegal System and Reality (A Retrospective Study in Menoufya Medicolegal Authority, Egypt). Ain Shams Journal of Forensic Medicine and Clinical Toxicology, 35(2), 23-33.

21. Hosseini S., Moslehi A., Hamidian S., Taghian S., (2014): The relation between chronic diseases and disability in elderly of Amirkola. Salmand Iran J Ageing.; 9(2):80-7.

22. Hosseinpoor, A., Bergen, N., Kostanjsek, N., Kowal, P., Officer, A., \& Chatterji, S., (2016): Socio-demographic patterns of disability among older adult populations of low-income and middle-income countries: results from World Health Survey. International journal of public health, 61(3), 337-345.

23. Katz S., Down, T., \& Cash, H., (1970): progress in the development of the index of ADL. Gerontologist 10:20-30.

24. Kessler, R., (2015): Epidemiology of women and depression. Journal of affective disorders, 74(1), 5-13.

25. Khan, Z., Singh, C., \& Khan, T., (2018): Correlates of physical disability in the elderly population of rural North India (Haryana). Journal of family \& community medicine, 25(3), 199.

26. Mary-Heck, G., Krief, H., Akrour, R., Ishida, M., Schurch, B., \& Lang, P., (2018): Screening for urinary incontinence in acute care for elders unit: comparative performance analysis of Katz's ADL and ICIQ-UISF. European Geriatric Medicine, 9(5), 579588.

27. Mozafari M., Salimi E., Bastami M., Azami M., Borji M., (2016): Disability status in the rural older adults in Ilam. J Gerontol. 1(1):4854.

28. Myers, D., Rogers, R., LeCrone, H., \& Kelley, K., (2019): The Behavioral Health Role in Nursing Facility Social Work. Journal of Applied Gerontology, 38(8), 1063-1095.

29. Nomura, S., Sakamoto, H., Glenn, S., Tsugawa, Y., Abe, S., Rahman, M., \& Kassebaum, N., (2017): Population health and regional variations of disease burden in Japan, 1990-2015: a systematic subnational analysis for the Global Burden of Disease Study. The Lancet, 390(10101), 1521-1538.

30. Norliana, I., (2016): Pattern and risk factors of functional limitation and physical disability among community-dwelling elderly in Kuala Pilah, Malaysia: A 12-month follow-up
study/Norliana Ismail (Doctoral dissertation, University Malaya.

31. Pattie, A., Gilleard, C., (1979): Manual of the Clifton Assessment Procedures for the Elderly (CAPE). Sevenoaks, Kent, UK: Hodder and Stoughton 22(1), 283.

32. Popolo, R., Smith, E., Lysaker, P., Lestingi, K., Cavallo, F., Melchiorre, L., \& Dimaggio, G., (2017): Metacognitive profiles in schizophrenia and bipolar disorder: comparisons with healthy controls and correlations with negative symptoms. Psychiatry research, 257, 45-50.

33. Pradhan, G., (2016): Social integration and its correlation with loneliness (Doctoral dissertation, Miami University).

34. Rasheedy D., (2015): Available services for the elderly in Egypt Geriatric services in egypt.p1.

35. Schmukle, S., Korndörfer, M., \& Egloff, B., (2019): No evidence that economic inequality moderates the effect of income on generosity. Proceedings of the National Academy of Sciences, 116(20), 9790-9795.

36. Sienko, R., (2017): An examination of attribute trade and weight stigma in online dating.

37. Tareque, M., Tiedt, A., Islam, T., Begum, S., \& Saito, Y., (2017): Gender differences in functional disability and self-care among seniors in Bangladesh. BMC geriatrics, 17(1), 177.

38. Vetvik, K., \& MacGregor, E., (2017): Sex differences in the epidemiology, clinical features, and pathophysiology of migraine. The Lancet Neurology, 16(1), 76-87.

39. Wang Z., Ning Li, Chao Guo, Lei Zhang, Gong Chen, \& Xiaoying Zheng, (2016): Inequities and psychiatry disability in transition among the elderly population from 1987 to 2006 in china ;95(36):e4779.

40. World Health Organization (WHO), (2015): disabilities, available at: https://www.who.int/topics/disabilities/en/.

41. World Health Organization. (2019): Global action plan on physical activity 2018-2030: more active people for a healthier world. World Health Organization.

42. Zhang, F., Li, D., Ahrentzen, S., \& Zhang, J., (2019): Assessing spatial disparities of accessibility to community-based service resources for Chinese older adults based on travel behavior: A city-wide study of Nanjing, China. Habitat International, 88, 101984. 